\title{
Effect of substrate particle size on burrowing of the juvenile freshwater pearl mussel Margaritifera margaritifera
}

\author{
Heini Hyvärinen (D) $\cdot$ Mari Saarinen-Valta $\cdot$ Eero Mäenpää $\cdot$ Jouni Taskinen
}

Received: 27 October 2020/Revised: 10 December 2020/ Accepted: 19 January 2021 / Published online: 10 February 2021

(C) The Author(s) 2021

\begin{abstract}
Juveniles of the endangered freshwater pearl mussel (FPM, Margaritifera margaritifera) live burrowed in stream substrate for the first years of their life. Fine sediments block water exchange within substrate and may cause juvenile mortality and recruitment failure. To better understand the connection between success of juvenile FPM and substrate particle size, it would be important to understand behavioural responses of FPM to varying substrate sizes at this critical life stage. We placed newly detached FPM juveniles in a 7-mm layer of sieved sand sorted into five sizes $(<120,120-200,200-250$, 250-500 and 500-650 $\mu \mathrm{m}$ ) each with 10 replicate dishes, 10 juveniles per dish, with burrowing status monitored for $96 \mathrm{~h}$. Mean dish-specific proportion burrowed (PB) was significantly affected by substrate size, increasing from $52 \%$ in the finest sand to $98 \%$ in the coarsest sand. Furthermore, the significant substrate $\times$ time interaction was observed due to dropped PB (30-34\%) in finest sand at 2-4 h time points. Thus,
\end{abstract}

Handling editor: Manuel Lopes Lima

H. Hyvärinen $(\varangle) \cdot$ M. Saarinen-Valta · J. Taskinen Department of Biological and Environmental Science, University of Jyväskylä, P.O. Box 35, 40014 Jyvaskyla, Finland

e-mail: heini.s.h.hyvarinen@jyu.fi

E. Mäenpää

West Finland Regional Environment Centre, P.O. Box 77, 67100 Kokkola, Finland results suggest a clear behavioural response by juvenile FPM to substrate size, with fine sediments triggering surfacing behaviour. Surfacing may indicate stress, can increase predation risk, and expose to drift and/or enable drift of juveniles.

Keywords Behaviour - Early juvenile stage · Endangered species $\cdot$ Sediment $\cdot$ Siltation $\cdot$ Unionida

\section{Introduction}

With their rapidly declining biodiversity, freshwater ecosystems include the most threatened types of habitats and biota worldwide (Ricciardi \& Rasmussen, 1999; Dudgeon et al., 2006; Geist, 2011). One of the main reasons for this decline is habitat degradation, with the fine sediment load considered as a major pressure (Richter et al., 1997; Henley et al., 2000; Denic \& Geist, 2015: Lopes-Lima et al., 2017). The freshwater mussels (Unionida) - globally the most endangered animal group (e.g. Bogan, 1993; Lydeard et al., 2004; Strayer et al., 2004; Régnier et al., 2009; Lopes-Lima et al., 2017, 2018) - are significantly dependent on the quality of stream/lake substrate because of their benthic ecology.

Freshwater mussels provide important ecosystem services contributing to nutrient cycling, water purification and bioturbation (Vaughn \& Hakenkamp, 2001; 
Howard \& Cuffey, 2006; Vaughn, 2018). Given their potentially high biomass and abundance (e.g. Kasprzak, 1985), the decline of freshwater mussel populations can have remarkable implications for ecosystem functioning (Howard \& Cuffey, 2006; Strayer, 2014). Like many other freshwater bivalves, the freshwater pearl mussel, Margaritifera margaritifera (Linnaeus, 1758), has declined substantially and is highly endangered or threatened throughout most of its distribution range (e.g. Young et al., 2001; Moorkens, 2011: Lopes-Lima et al., 2017, 2018). Fulfilling the characteristics of an indicator, flagship, umbrella and keystone species, M. margaritifera is an ideal target species for conserving aquatic ecosystem functioning (Geist, 2010).

Margaritifera margaritifera has a larval stage, glochidium, which is parasitic on salmonid fish, Salmo trutta Linnaeus, 1758 and S. salar Linnaeus, 1758 (Salonen et al., 2016, 2017). After being released to the water by female mussels in autumn, glochidia attach to the body of host fish where they encyst. The glochidia remain attached to the host fish for several months during which they grow and develop into small mussels, excyst, drop off and start their benthic life as a juveniles (Young \& Williams, 1984; Salonen et al., 2017).

The post-parasitic, juvenile stage of $M$. margaritifera burrows within the stream substrate for a period of several years, a phase which is considered to be critical stage in the life cycle of $M$. margaritifera (Bauer, 1988; Buddensiek et al., 1993) and all Unionida mussels. In many declining $M$. margaririfera populations, mussels are able to produce glochidia, but juvenile recruitment has not been reported for decades (Lopes-Lima et al., 2017; Oulasvirta et al., 2017). In addition, adult M. margaritifera are found over a wider range of physical conditions than juveniles (Buddensiek et al., 1993; Hastie et al., 2000), suggesting that juvenile $M$. margaririfera are more susceptible to adverse environmental conditions than the adults. Studies on the oxygen needs of juvenile freshwater mussels indicate that their behaviour and survival are affected at much higher oxygen concentrations than those affecting adult mussels (Dimock \& Wright, 1993; Sparks \& Strayer, 1998). Above all, dissolved oxygen concentrations are much lower within the substrate than in the free waterbody (Buddensiek et al., 1993; Strayer et al., 1997), and during summer period, temperatures within the substrate are cooler than at the surface of the sediment (Gough et al., 2012). Thus, the interstitial habitat of juvenile mussels differs vastly from the surface environment inhabited by adult mussels and calls for examination on its own.

Several studies indicate that stream bed quality is the most important factor limiting the recruitment of M. margaritifera (e.g. Geist \& Auerswald, 2007; Österling et al., 2010; Denic \& Geist, 2015). Even slight changes in the stream hydrological processes influence the microhabitats within the stream bed and may result in critical habitat degradation. In their postparasitic phase, juvenile $M$. margaritifera depend on a continuously aerated interstitial space within the stream substrate (Buddensiek et al., 1993; Geist \& Auerswald, 2007). Fine sediment depositions alter the substrate composition and change the suitability of the substrate for juvenile mussels (e.g. Wood \& Armitage, 1997; Henley et al., 2000). Clogging the top layer of substrate, fine sediments impede exchange between the free water body and interstitial water (Munn \& Meyer, 1988; Ryan, 1991; Geist \& Auerswald, 2007), reducing the well-aerated habitat spaces required by mussel juveniles (Wood \& Armitage, 1997; Geist \& Auerswald, 2007).

Stream sites with successful M. margaritifera juvenile recruitment are characterized by coarser and better sorted substrates with low quantities of fines (e.g. Buddensiek et al., 1993; Hastie et al., 2000; Geist \& Auerswald, 2007; Österling \& Högberg, 2014). Thus, the negative dependence between the recruitment of juvenile $M$. margaritifera and fine sediments has been shown clearly, but juvenile behaviour when exposed to substrates of varying particle size has not been studied. Knowing the behavioural responses of M. margaritifera juveniles to different particle sizes of substrate would increase our understanding of the mechanisms behind the negative effects of fine sediments on juvenile freshwater mussels. This knowledge would also contribute to the research priorities for freshwater mussels listed by FerreiraRodríguez et al. (2019), one of them being species response to the effects of land-use change, such as sedimentation.

Burrowing behaviour of adult Unionida mussels has been studied from many angles (e.g. Lewis \& Riebel, 1984; Di Maio \& Corkum, 1997; Watters et al., 2001; Saarinen \& Taskinen, 2003; Taskinen \& Saarinen, 2006; Allen \& Vaughn, 2009). However, 
only a few studies have focused solely on the burrowing behaviour of juvenile Unionida (Yeager et al., 1994; Sparks \& Strayer, 1998; Archambault et al., 2013, 2014; French \& Ackerman, 2014; Kemble et al., 2020), and even fewer have examined the burrowing behaviour of margaritiferids (Bílý et al., 2020). Experimental studies on a total of six Unionidae species by Yeager et al. (1994) and Kemble et al. (2020), showed that almost all juveniles burrowed into test sediment within $20 \mathrm{~min}$. Low oxygen, high temperature and drought have been found to cause surfacing and other stress behaviours in Unionida juveniles (Sparks \& Strayer 1998; Archambault et al., 2013, 2014). To our knowledge, only one study prior to ours has examined the burrowing behaviour of juvenile M. margaritifera; Bílý et al. (2020) found recently that 1 -year-old $M$. margaritifera tended to burrow to depth of $2-3 \mathrm{~cm}$ in $12 \mathrm{~cm}$ substrate tubes, installed in natural river bed, with sand grain size of $1.0-2.0 \mathrm{~mm}$. Low oxygen conditions within the test substrate were related to surfacing and low survival rates of juveniles. However, burrowing behaviour of recently detached ( 0 years old) $M$. margaritifera juveniles has not been previously studied. The aim of the present study was to fill this gap, as it is important to know the behavioural responses of juvenile $M$. margaritifera to substrate quality immediately in the beginning of their benthic life.

In this study, we investigated experimentally the effect of substrate particle size on burrowing behaviour of freshly metamorphosed juvenile $M$. margaritifera. We aimed to determine how fast $M$. margaritifera juveniles burrow into the substrate and do they stay burrowed or re-surface. Our hypotheses were as follows: (1) Based on the results of comparative field studies on the relationship between $M$. margaritifera recruitment and sediment quality (e.g. Buddensiek et al., 1993; Hastie et al., 2000; Geist \& Auerswald, 2007; Österling et al., 2010), and on the results of unionid juveniles indicating that surfacing behaviour of juveniles is a sign of stress (Sparks \& Strayer, 1998; Archambault et al., 2013, 2014), we hypothesized that - in the current range of particle sizes - proportion of burrowed juveniles would be negatively related to fine substrates, and thus, the percentage of burrowed juveniles was predicted to be higher in coarse substrates. (2) Based on the previous results on burrowing of Unionidae juveniles (Yeager et al., 1994; Kemble et al., 2020), we hypothesized that a large majority of $M$. margaritifera juveniles would burrow within $30 \mathrm{~min}$ of time.

\section{Materials and methods}

To receive juvenile $M$. margaritifera, $0+$ year old brook trout, Salmo trutta, fry $(N=500$, River Ohtajoki, tributary of River Iijoki stock, Finland) were transported to River Haapuanoja (tributary of River Iijoki), a known $M$. margaritifera river (Salonen et al. 2017), on September 9, 2006, and put into five fish cages. M. margaritifera is known to release glochidia during the last half of September in this area (Salonen et al. 2017). Fish cages were submerged in the river, to expose the fish to naturally shed glochidia, and covered for shading. On October 17, 2006, the fish were transported to a laboratory for inspection. Infection success was confirmed by sampling two fish, which were infected with 300-500 glochidia when the gills were inspected microscopically. The remaining fish were kept over winter in groundwater (collected from a well) in a 10001 tank at $8^{\circ} \mathrm{C}$ and fed with commercial fish food pellets. The tank was siphoned every 2-3 days once the juveniles began dropping from the host fish in June, 2007.

On June 13, 2007, newly transformed juveniles $(N=550$, mean length $=363 \pm 11 \mu \mathrm{m})$ were transported in 1-l containers in $8^{\circ} \mathrm{C}$ groundwater to the laboratory of Department of Biology and Environmental Science, University of Jyväskylä, where the experiment was performed. Juveniles were acclimated to the new water conditions by slowly adding water from the River Ähtävänjoki (Finland) to containers. Water was added to the juvenile containers 1-3 times an hour for $24 \mathrm{~h}$ until all the groundwater had been replaced with river water.

Bottom substrate collected from a sandy patch of the littoral zone of Lake Jyväsjärvi (Finland) was washed, dried, and sorted with sieves into five size classes: (1) $<120 \mu \mathrm{m}$; (2) $120-200 \mu \mathrm{m}$; (3) 200-250 $\mu \mathrm{m}$; (4) 250-500 $\mu \mathrm{m}$; and (5) 500-650 $\mu \mathrm{m}$. These size classes correspond substrate sizes from fine sand to coarse sand (grain size definitions: ISO 14688-1:2018, 2018). Each treatment was applied to ten replicates and ten juveniles were placed in each replicate, a $60 \mathrm{~mm}$ (diameter) $\times 15 \mathrm{~mm}$ (height) plastic dish. Each dish was filled with substrate and River Ähtävänjoki water so that the total height of 
substrate and water was $12 \mathrm{~mm}$, of which $7 \mathrm{~mm}$ was substrate. Experiment was performed at $17-18^{\circ} \mathrm{C}$ in $12 \mathrm{~h}$ dark: $12 \mathrm{~h}$ light conditions without changing the water. After placing the juveniles in random order on substrates, using a pipette, juveniles were monitored by observing them under a dissection microscope with an additional light source. The visible, not-burrowed juveniles were counted at $0.5,1,2,4,72$, and $96 \mathrm{~h}$ time points. After the experiment, surviving juveniles were counted; only one juvenile died during the experiment.

For statistical analyses, burrowing percentage, i.e. the proportion of burrowed individuals, was used as the response variable, and single dish (containing 10 juveniles) was used as the statistical unit. The effect of substrate size on the proportion of burrowed individuals was tested using repeated measures analysis of variance (RM-ANOVA) with time (0.5, 1, 2, 4, 72 and $96 \mathrm{~h}$ ) as within-subject factor and substrate type (five substrate size classes) as a between-subject factor. To meet the assumptions of ANOVA, an arc-sin transformation was performed on proportion data before statistical analysis. If the sphericity assumption of RM-ANOVA was not met (Mauchly's $W=0.569$, $P<0.05)$, the Greenhouse-Geisser correction for the F-statistics was performed. The assumptions of normality and equality of error variances were not completely fulfilled because in the coarsest substrate class $500-650 \mu \mathrm{m}$, all juveniles were completely burrowed at the last three time points. ANOVA is robust for normality assumption violation, but if homogeneity-of-variance assumption is violated in ANOVA, the significance level will be underestimated, increasing the risk of falsely rejecting the null hypothesis. However, e.g. when analysing the effect of time on the proportion of burrowed juveniles in the coarsest substrate, the null hypothesis was not rejected (see "Results"), suggesting that the homogeneity-ofvariance assumption violation did not bias the results. Paired (Post Hoc) tests were performed to analyse differences between substrate size classes over the 96-h experiment and between time points within each substrate size treatment. $P$ values of these paired tests were corrected using LSD (least significant difference) adjustment because of multiple comparisons. Statistical analyses were performed using IBM SPSS Statistics for Windows 24.0 (SPSS inc., Chicago, IL, USA). Means are given with \pm standard error (S.E.) of the mean.

\section{Results}

Juveniles burrowed quickly in the beginning of the experiment. After $30 \mathrm{~min}$, the mean \pm S.E. proportion of burrowed individuals over all replicates was $80.6 \pm 2.4 \%$, ranging from $65 \pm 5.4 \%$ in the finest sand to $95 \pm 5.4 \%$ in the coarsest sand (Fig. 1).

When assessed over the whole experiment, the effect of substrate size on juvenile burrowing was statistically significant (RM-ANOVA, $F_{4,45}=127.77$, $P<0.001)$. During the 96-h experiment, the lowest mean $( \pm$ S.E.) proportion of burrowed individuals $(52.0 \pm 2.8 \%)$ was in the finest sand substrate, size $<120 \mu \mathrm{m}$; pairwise comparisons with LSD adjustment revealed that the mean percent of burrowed juveniles in this substrate size class was statistically significantly lower than in any other (coarser) sand size $(P<0.001)$ (Fig. 1). Next lowest mean proportions of burrowed individuals, $72.3 \pm 2.0$ and $78.3 \pm 1.6 \%$, were observed in the substrate size classes of 200-250 and 120-200 $\mu \mathrm{m}$, respectively, which did not differ from each other but differed significantly from other substrate classes in pairwise comparisons (LSD adjusted $P<0.001$ in all cases).

The highest mean $( \pm$ S.E.) proportions of burrowed individuals over the 96-h experiment, $94.2 \pm 1.2 \%$ and $98.0 \pm 0.7 \%$, were observed in the coarsest substrate size classes, 250-500 $\mu \mathrm{m}$ and 500-650 $\mu \mathrm{m}$, respectively (Fig. 1). Paired comparisons revealed that these two substrates differed from each other statistically only marginally significantly by their mean percent burrowed over the whole experiment (LSD adjusted $P=0.057$ ), but they both differed significantly from all other substrate sizes (LSD adjusted $P<0.001$ in all cases) (Fig. 1).

There was a statistically significant interaction between 'time' and 'substrate size' (RM-ANOVA, $\left.F_{20,225}=2.599, P<0.001\right)$, indicating that the timedependent changes in the burrowing percentages were not equal in all substrate size classes. In the finest sand substrate, the lowest proportion of burrowed juveniles (of the whole experiment), $30 \pm 4.0 \%$, was observed at the time point $2 \mathrm{~h}$ and the maximum percent burrowed in this substrate was $67 \pm 4.7 \%$ at $96 \mathrm{~h}$, which was observed at the end of the experiment (Fig. 1), repeated measures ANOVA performed for the finest sand substrate, $<120 \mu \mathrm{m}$, revealed a significant effect of time on the percent of burrowed juveniles $\left(F_{5}, \quad 45=8.154, \quad P<0.001\right)$. Pairwise 


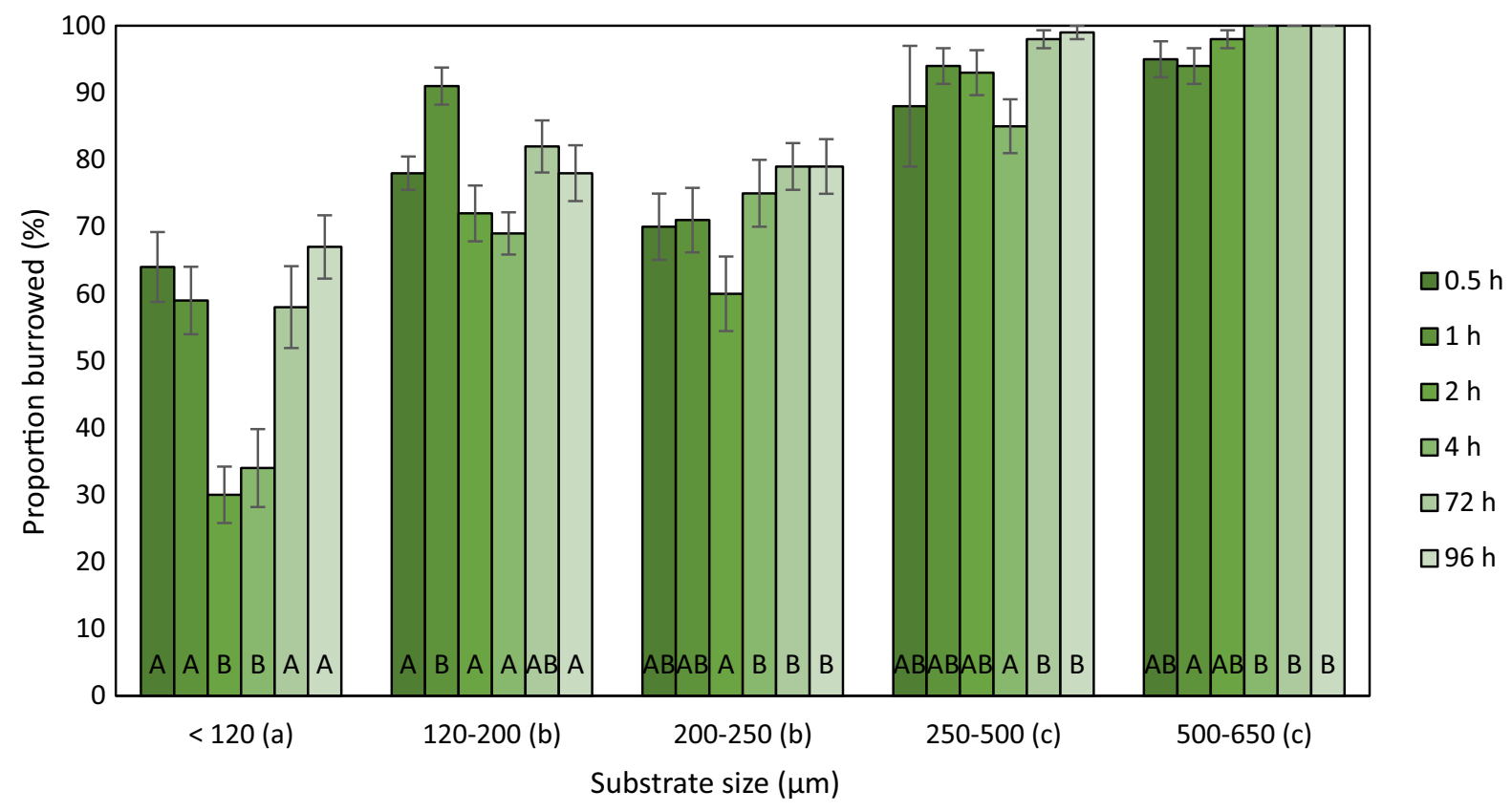

Fig. 1 Proportion (\%) of burrowed juvenile M. margaritifera in five substrate sizes at six time points. Each bar represents mean $( \pm \mathrm{SE})$ of 10 replicate dishes; each dish included 10 juvenile mussels. Time points (i.e. bars) marked with the same capital letter did not differ statistically significantly from each other

comparisons indicated that the time points 2 and $4 \mathrm{~h}$ did not differ from each other (LSD adjusted $P=0.492$ ) while they both differ from all other time points (LSD adjusted $P$ values ranging from $P<0.001$ to $P=0.020$ ). Also in the second finest sand substrate, $120-200 \mu \mathrm{m}$, there was a significant effect of time on juvenile burrowing (RM-ANOVA, $F_{5,45}=5.256, P=0.001$ ) but the temporal pattern was totally different as compared to the finest sand substrate. In the second finest sand substrate, percent burrowed was the highest at the time point $1 \mathrm{~h}$, differing significantly from all other time points (LSD adjusted $P$ values ranging from $P=0.002$ to $P=0.019$ ) except for time $72 \mathrm{~h}$ (Fig. 1).

By contrast, in the coarser sand substrates, the statistically significant temporal variation in the percentages of burrowed juveniles was not found. There were no significant temporal differences in the percent of burrowed juveniles in the substrate size class 200-250 $\mu \mathrm{m}$ (RM-ANOVA, $F_{5}, 45=2.018$, $P=0.094)$, in the substrate size class $250-500 \mu \mathrm{m}$ (RM-ANOVA with a Greenhouse-Geisser correction, $\left.F_{5,45}=2.109, P=0.125\right)$ or in the substrate size class within a substrate size class. Similarly, substrate sizes marked with the same small case letter (in parentheses) did not differ from each other by their mean proportion burrowed over all time points. Proportion of burrowed juveniles increased with substrate particle size

500-650 $\mu \mathrm{m}$ (RM-ANOVA with a Greenhouse-Geisser correction, $F_{5}, 45=2.858, P=0.072$ ). In the coarsest sand, the proportion of burrowed juveniles varied from $94 \pm 2.7 \%$ at $1 \mathrm{~h}$ to $100.0 \%$ at 4,72 , and $96 \mathrm{~h}$ (Fig. 1). Thus, in the coarsest sand, all $M$. margaritifera juveniles were completely burrowed by $4 \mathrm{~h}$ from the start of the experiment and stayed completely burrowed after that.

These contrasting temporal patterns, especially the marked decrease in the percent burrowed at 2-4 h after the start of the experiment in the finest sediment as compared to the constant, high percent burrowed in the coarsest sand substrates probably explains the significant 'time' $\times$ 'substrate size' interaction observed in the data.

\section{Discussion}

We found that the proportion of burrowed juvenile $M$. margaritifera was dependent on the size of the available substrate. The hypotheses were supported as (1) most juveniles had burrowed in $30 \mathrm{~min}$ in all 
substrate sizes and (2) more juveniles stayed burrowed in coarse sand than in fine sand. Thus, the burrowing speed was in the same range as in the previous studies with Unionidae juveniles (Yeager et al., 1994; Kemble et al., 2020). In addition, if surfacing behaviour of juveniles is considered as a sign of stress, as suggested by studies of Sparks \& Strayer (1998) and Archambault et al. (2013, 2014), our results indicate that $M$. margaritifera juveniles were less stressed in the coarser sand substrates of the present experiment.

Despite able to burrow into the finest sand, juveniles resurfaced after a couple of hours, suggesting that juveniles have an ability to discriminate a poor habitat from a good one. Resurfacing from an unsuitable site not only exposes juveniles to the current with the risk of becoming dislodged and being washed away, but it also gives juveniles a chance to drift to a more suitable site, as also suggested by Bílý et al. (2020). Conversely, at suitable sites, it is beneficial for an individual mussel to avoid exposure to the stream current by staying burrowed. Laboratory experiments show that exposed juveniles are vulnerable to predation (Lin, 1991; Klocker \& Strayer, 2004). Thus, if a suitable interstitial habitat is not available for burrowing, juveniles may be susceptible to an increased predation rate.

The results of this study are consistent with field studies in which fine sediments are associated with poor recruitment of juvenile $M$. margaritifera (Young \& Williams, 1983; Hastie et al., 2000; Geist \& Auerswald, 2007; Österling \& Högberg, 2014). Deposition of suspended fine particles is known to deteriorate the microhabitats of interstitial layer by, e.g. lowering concentrations of interstitial dissolved oxygen (e.g. Munn \& Meyer, 1988; Ryan, 1991; Geist \& Auerswald, 2007). Juvenile freshwater mussels have been shown to be sensitive to low concentrations of dissolved oxygen (Dimock \& Wright, 1993; Sparks \& Strayer, 1998). The results of the present study as well as earlier work (Sparks \& Strayer, 1998; Bílý et al., 2020) suggest that juveniles move to the surface as a response for avoiding an oxygen-depleted or otherwise unsuitable habitat. This hypothesis is in accordance with studies showing adverse physiological effects of fine sediments on freshwater mussels. Increased turbidity derived from fine sediments can interfere with filter-feeding (Aldridge et al., 1987), reduce growth (Österling et al., 2010) and lower attachment and metamorphosis success (Gascho Landis et al., 2013) of freshawater mussels.

Recently, Bílý et al. (2020) showed experimentally that 1-year old $M$. margaritifera juveniles avoided deeper, low-oxygenated zones of the 12-cm substrate tube. Therefore, it is possible that the surfacing behaviour of $M$. margaritifera juveniles in fine sand in the present study was associated with decreased oxygen in fine sediment treatments. However, a steep oxygen gradient is not expected to take place in a relatively shallow $(7 \mathrm{~mm})$ sediment layer of our study. In addition, juveniles re-burrowed in the finest sediments during the course of time, which would indicate that substrate quality, rather that oxygen concentration, will explain the results. More importantly, our results verify that the burrowing tendency of young $M$. margaritifera is developed and effective as soon as they have detached from the fish host.

The results of this study indicate that newly metamorphosed juvenile $M$. margaritifera are, to certain extent, able to avoid poor habitats by sensing their surroundings within the substrate and surfacing at unsuitable sites. Further studies are needed to determine whether juvenile $M$. margaritifera are able to move horizontally within different types of substrates and whether their movement shows active habitat selection. Zajac \& Zajac (2011) suggested that movements of adult Unio crassus Philipsson, 1788 were prompted by the avoidance of unsuitable sites, but the extent to which newly metamorphosed Unionida juveniles are able to influence their location is largely unstudied.

Our results show that substrate particle size is an essential measure of M. margaritifera habitat quality. If burrowing is assumed as a central feature of juvenile M. margaritifera behaviour, it was clear that-within the range of tested particle sizes-the coarse sand (500-650 $\mu \mathrm{m})$ can be ranked as the best substrate for newly metamorphosed juveniles. In the coarse sand, all $M$. margaritifera juveniles were completely burrowed by $4 \mathrm{~h}$ from the start of the experiment and stayed completely burrowed after that until the end of the 96-h experiment.

Even though the present study did not examine juvenile survival related to substrate particle size, it is noteworthy that only one of the 500 newly excysted individuals died during the $96 \mathrm{~h}$ experiment. This suggests that the juveniles and the experimental 
conditions were of equal, high quality in all treatments throughout the experiment.

Restoration of stream substrate is costly and requires long-term focus on catchment land use, but it is probably the most important conservation action for restoring threatened populations of M. margaritifera. The decline of Unionida mussels has prompted a number of studies on captive breeding of Unionida juveniles (e.g. Jones \& Neves, 2002; Lima et al., 2012; Kunz et al., 2020; Hyvärinen et al., 2020). Culturing mussel juveniles can be the only way to conserve the most threatened populations and to retain the evolutionary and genetic potential of the species (Geist \& Kuehn, 2005; Geist \& Kuehn, 2005), but it cannot replace habitat restoration as a conservation measure. As suggested by Moorkens \& Killeen (2014), introducing captive-bred juveniles to suitable stream sites could maintain an endangered population until longterm stream restoration has sufficiently improved the mussel habitat. Identifying stream sites with suitable substrate conditions is essential for the success of captive breeding initiatives aiming to restore the endangered populations of $M$. margaritifera. In providing new information about the behavioural responses of juveniles to varying substrate particle sizes, present study is a step towards understanding the essential habitat requirements of juvenile $M$. margaritifera - a prerequisite for successful conservation of this endangered species.

Acknowledgements The study was financed by the Ministry of Agriculture and Forestry in Finland (JT), the Maj and Tor Nessling Foundation (MS-V), the Ähtävänjoki Foundation (EM), Finnish Cultural Foundation's Central Finland Regional Fund $(\mathrm{HH})$, the Finnish Foundation for Nature Conservation $(\mathrm{HH})$, The Finnish Concordia Fund $(\mathrm{HH})$, Raija and Ossi Tuuliainen Foundation (JT) and EU Kolarctic Cross Border Collaboration CBC Programme 2014-2020 (Project SALMUS/ KO1017) (JT). We thank Roger Jones for valuable comments on the earlier version of the manuscript.

Author contributions All authors listed have made a substantial and direct contribution to the research process and approved the submitted version of the manuscript. JT and MS-V conceived the research question and methods. EM arranged the juvenile mussels and MS-V performed the experiment. JT and MS-V analysed the data, while $\mathrm{HH}$ prepared the figure. HH wrote the manuscript with significant contributions by MS-V and JT.

Funding Open Access funding provided by University of Jyväskylä (JYU). The study was financed by the Ministry of Agriculture and Forestry in Finland (JT), the Maj and Tor
Nessling Foundation (MS-V), the Ähtävänjoki Foundation (EM), Finnish Cultural Foundation's Central Finland Regional Fund $(\mathrm{HH})$, the Finnish Foundation for Nature Conservation $(\mathrm{HH})$, The Finnish Concordia Fund $(\mathrm{HH})$, Raija and Ossi Tuuliainen Foundation (JT), and EU Kolarctic Cross Border Collaboration CBC Programme 2014-2020 (Project SALMUS/ KO1017) (JT).

\section{Compliance with ethical standards}

Conflict of interest The authors have no conflicts of interest to declare that are relevant to the content of this article.

Ethical approval Infection and maintenance of fish were done under a permission by the Ethical Committee for Animal Research of the Finnish Game and Fisheries Research Institute (License no. 13/06). Permission for collection of glochidia and the use of juveniles in experiments was granted by the North Ostrobothnia Regional Environment Centre (License PPO2006-L-540-254).

Open Access This article is licensed under a Creative Commons Attribution 4.0 International License, which permits use, sharing, adaptation, distribution and reproduction in any medium or format, as long as you give appropriate credit to the original author(s) and the source, provide a link to the Creative Commons licence, and indicate if changes were made. The images or other third party material in this article are included in the article's Creative Commons licence, unless indicated otherwise in a credit line to the material. If material is not included in the article's Creative Commons licence and your intended use is not permitted by statutory regulation or exceeds the permitted use, you will need to obtain permission directly from the copyright holder. To view a copy of this licence, visit http://creativecommons.org/licenses/by/4.0/.

\section{References}

Aldridge, D. W., B. S. Payne \& A. C. Miller, 1987. The effects of intermittent exposure to suspended solids and turbulence on three species of freshwater mussels. Environmental Pollution 45: 17-28.

Allen, D. C. \& C. C. Vaughn, 2009. Burrowing behavior of freshwater mussels in experimentally manipulated communities. Journal of the North American Benthological Society 28: 93-100.

Archambault, J. M., W. Gregory Cope \& T. J. Kwak, 2013. Burrowing, byssus, and biomarkers: behavioral and physiological indicators of sublethal thermal stress in freshwater mussels (Unionidae). Marine and Freshwater Behaviour and Physiology 46: 229-250.

Archambault, J. M., W. G. Cope \& T. J. Kwak, 2014. Survival and behaviour of juvenile unionid mussels exposed to thermal stress and dewatering in the presence of a sediment temperature gradient. Freshwater Biology 59: 601-613.

Bauer, G., 1988. Threats to the freshwater pearl mussel Margaritifera margaritifera L. in Central Europe. Biological Conservation 45: 239-253. 
Bílý, M., O. Simon, V. Barák \& V. Jahelková, 2020. Occurrence depth of juvenile freshwater pearl mussels (Margaritifera margaritifera) in a river bed tested by experimental mesh tubes. Hydrobiologia. https://doi.org/10.1007/s10750-02004298-8.

Bogan, A. E., 1993. Freshwater bivalve extinctions (Mollusca: Unionoida): a search for causes. Integrative and Comparative Biology 33: 599-609.

Buddensiek, V., S. Engel, Fleischauer-Rössing \& K. Wächtler, 1993. Studies on the chemistry of interstitial water taken from defined horizons in the fine sediments of bivalve habitats in several northern German lowland waters. II: Microhabitats of Margaritifera margaritifera L., Unio crassus (Philipsson) and Unio tumidus Philipsson. Archive for Hydrobiologie 127: 151-166.

Denic, M. \& J. Geist, 2015. Linking stream sediment deposition and aquatic habitat quality in pearl mussel streams: implications for conservation. River Research and Applications 31: 943-952.

Di Maio, J. \& L. D. Corkum, 1997. Patterns of orientation in Unionids as a function of rivers with differing hydrological variability. Journal of Molluscan Studies Oxford Academic 63: 531-539.

Dimock, R. V. \& A. H. Wright, 1993. Sensitivity of juvenile freshwater mussels to hypoxic, thermal and acid stress. Journal of the Elisha Mitchell Scientific Society 109: 183-192.

Dudgeon, D., A. H. Arthington, M. O. Gessner, Z.-I. Kawabata, D. J. Knowler, C. Lévêque, R. J. Naiman, A.-H. PrieurRichard, D. Soto, M. L. J. Stiassny \& C. A. Sullivan, 2006. Freshwater biodiversity: importance, threats, status and conservation challenges. Biological Reviews of the Cambridge Philosophical Society 81: 163-182.

Ferreira-Rodríguez, N., Y. B. Akiyama, O. V. Aksenova, R. Araujo, M. Christopher Barnhart, Y. V. Bespalaya, A. E. Bogan, I. N. Bolotov, P. B. Budha, C. Clavijo, S. J. Clearwater, G. Darrigran, V. T. Do, K. Douda, E. Froufe, C. Gumpinger, L. Henrikson, C. L. Humphrey, N. A. Johnson, O. Klishko, M. W. Klunzinger, S. Kovitvadhi, U. Kovitvadhi, J. Lajtner, M. Lopes-Lima, E. A. Moorkens, S. Nagayama, K.-O. Nagel, M. Nakano, J. N. Negishi, P. Ondina, P. Oulasvirta, V. Prié, N. Riccardi, M. Rudzīte, F. Sheldon, R. Sousa, D. L. Strayer, M. Takeuchi, J. Taskinen, A. Teixeira, J. S. Tiemann, M. Urbańska, S. Varandas, M. V. Vinarski, B. J. Wicklow, T. Zając \& C. C. Vaughn, 2019. Research priorities for freshwater mussel conservation assessment. Biological Conservation 231: 77-87.

French, S. K. \& J. D. Ackerman, 2014. Responses of newly settled juvenile mussels to bed shear stress: implications for dispersal. Freshwater Science 33: 46-55.

Gascho Landis, A., W. Haag \& J. Stoeckel, 2013. High suspended solids as a factor in reproductive failure of a freshwater mussel. Freshwater Science 32: 70-81.

Geist, J., 2010. Strategies for the conservation of endangered freshwater pearl mussels (Margaritifera margaritifera L.): a synthesis of Conservation Genetics and Ecology. Hydrobiologia 644: 69-88.

Geist, J., 2011. Integrative freshwater ecology and biodiversity conservation. Ecological Indicators 11: 1507-1516.
Geist, J. \& K. Auerswald, 2007. Physicochemical stream bed characteristics and recruitment of the freshwater pearl mussel (Margaritifera margaritifera). Freshwater Biology 52: 2299-2316.

Geist, J. \& R. Kuehn, 2005. Genetic diversity and differentiation of central European freshwater pearl mussel (Margaritifera margaritifera L.) populations: implications for conservation and management. Molecular Ecology 14: 425-439.

Gough, H. M., A. M. Gascho Landis \& J. A. Stoeckel, 2012. Behaviour and physiology are linked in the responses of freshwater mussels to drought: differential mussel responses to drought. Freshwater Biology 57: 2356-2366.

Hastie, L. C., P. J. Boon \& M. R. Young, 2000. Physical microhabitat requirements of freshwater pearl mussels, Margaritifera margaritifera (L.). Hydrobiologia 429: 59-71.

Henley, W. F., M. A. Patterson, R. J. Neves \& A. D. Lemly, 2000. Effects of sedimentation and turbidity on lotic food webs: a concise review for natural resource managers. Reviews in Fisheries Science 8: 125-139.

Howard, J. K. \& K. M. Cuffey, 2006. The functional role of native freshwater mussels in the fluvial benthic environment. Freshwater Biology 51: 460-474.

Hyvärinen, H. S. H., M. M. R. Chowdhury \& J. Taskinen, 2020. Pulsed flow-through cultivation of Margaritifera margaritifera: effects of water source and food quantity on the survival and growth of juveniles. Hydrobiologia. https:// doi.org/10.1007/s10750-020-04225-x.

ISO 14688-1:2018, 2018. Geotechnical Investigation and Testing - Identification and Classification of Soil - Part 1: Identification and Description. International Organization for Standardization, London.

Jones, J. W. \& R. J. Neves, 2002. life history and propagation of the endangered fanshell Pearlymussel, Cyprogenia stegaria Rafinesque (Bivalvia: Unionidae). Journal of the North American Benthological Society 21: 76-88.

Kasprzak, K., 1985. Occurrence and role of the family Unionidae (Mollusca, Bivalvia) in the eutrophic Lake Zbechy and its outflow canal. Acta Hydrobiologica 27: 351-370.

Kemble, N. E., J. M. Besser, J. Steevens \& J. P. Hughes, 2020. Assessment of burrowing behavior of freshwater juvenile mussels in sediment. Freshwater Mollusk Biology and Conservation 23: 69-81.

Klocker, C. A. \& D. L. Strayer, 2004. Interactions among an invasive crayfish (Orconectes rusticus), a native crayfish (Orconectes limosus), and native bivalves (Sphaeriidae and Unionidae). Northeastern Naturalist Eagle Hill Institute 11: 167-178.

Kunz, J., E. Brunson, M. Barnhart, E. Glidewell, N. Wang \& C. Ingersoll, 2020. Pulsed flow-through auto-feeding beaker systems for the laboratory culture of juvenile freshwater mussels. Aquaculture 520: 734959.

Lewis, J. B. \& P. N. Riebel, 1984. The effect of substrate on burrowing in freshwater mussels (Unionidae). Canadian Journal of Zoology 62: 2023-2025.

Lima, P., M. L. Lima, U. Kovitvadhi, S. Kovitvadhi, C. Owen \& J. Machado, 2012. A review on the "in vitro" culture of freshwater mussels (Unionoida). Hydrobiologia 691: 21-33. 
Lin, J., 1991. Predator-prey interactions between blue crabs and ribbed mussels living in clumps. Estuarine, Coastal and Shelf Science 32: 61-69.

Lopes-Lima, M., R. Sousa, J. Geist, D. C. Aldridge, R. Araujo, J. Bergengren, Y. Bespalaya, E. Bódis, L. Burlakova, D. V. Damme, K. Douda, E. Froufe, D. Georgiev, C. Gumpinger, A. Karatayev, Ü. Kebapçi, I. Killeen, J. Lajtner, B. M. Larsen, R. Lauceri, A. Legakis, S. Lois, S. Lundberg, E. Moorkens, G. Motte, K.-O. Nagel, P. Ondina, A. Outeiro, M. Paunovic, V. Prié, T. von Proschwitz, N. Riccardi, M. Rudzīte, M. Rudzītis, C. Scheder, M. Seddon, H. Şereflişan, V. Simić, S. Sokolova, K. Stoeckl, J. Taskinen, A. Teixeira, F. Thielen, T. Trichkova, S. Varandas, H. Vicentini, K. Zajac, T. Zajac \& S. Zogaris, 2017. Conservation status of freshwater mussels in Europe: state of the art and future challenges. Biological Reviews 92: 572-607.

Lopes-Lima, M., L. E. Burlakova, A. Y. Karatayev, K. Mehler, M. Seddon \& R. Sousa, 2018. Conservation of freshwater bivalves at the global scale: diversity, threats and research needs. Hydrobiologia 810: 1-14.

Lydeard, C., R. H. Cowie, W. F. Ponder, A. E. Bogan, P. Bouchet, S. A. Clark, K. S. Cummings, T. J. Frest, O. Gargominy, D. G. Herbert, R. Hershler, K. E. Perez, B. Roth, M. Seddon, E. E. Strong \& F. G. Thompson, 2004. The global decline of nonmarine mollusks. BioScience American Institute of Biological Sciences 54: 321-330.

Moorkens, E. 2011. Margaritifera margaritifera. The IUCN Red List of Threatened Species 2011: e.T12799A3382660. Downloaded on 10 April 2020.

Moorkens, E. A. \& I. J. Killeen, 2014. Assessing near-bed velocity in a recruiting population of the endangered freshwater pearl mussel (Margaritifera margaritifera) in Ireland. Aquatic Conservation: Marine and Freshwater Ecosystems 24: 853-862.

Munn, N. \& J. Meyer, 1988. Rapid flow through the sediments of a headwater stream in the southern Appalachians. Freshwater Biology 20: 235-240.

Österling, M. \& J.-O. Högberg, 2014. The impact of land use on the mussel Margaritifera margaritifera and its host fish Salmo trutta. Hydrobiologia 735: 213-220.

Österling, M. E., B. L. Arvidsson \& L. A. Greenberg, 2010. Habitat degradation and the decline of the threatened mussel Margaritifera margaritifera: influence of turbidity and sedimentation on the mussel and its host. Journal of Applied Ecology 47: 759-768.

Oulasvirta, P., J. Leinikki \& J. Syväranta, 2017. Freshwater pearl mussel in Finland-current status and future prospects. Biology Bulletin 44: 81-91.

Régnier, C., B. Fontaine \& P. Bouchet, 2009. Not knowing, not recording, not listing: numerous unnoticed mollusk extinctions. Conservation Biology 23: 1214-1221.

Ricciardi, A. \& J. B. Rasmussen, 1999. Extinction rates of North American freshwater fauna. Conservation Biology 13: 1220-1222.

Richter, B. D., D. P. Braun, M. A. Mendelson \& L. L. Master, 1997. Threats to imperiled freshwater fauna. Conservation Biology 11: 1081-1093.

Ryan, P. A., 1991. Environmental effects of sediment on New Zealand streams: a review. New Zealand Journal of Marine and Freshwater Research 25: 207-221.
Saarinen, M. \& J. Taskinen, 2003. Burrowing and crawling behavious of three species of unionidae in Finland. Journal of Molluscan Studies 69: 81-86.

Salonen, J. K., T. J. Marjomäki \& J. Taskinen, 2016. An alien fish threatens an endangered parasitic bivalve: the relationship between brook trout (Salvelinus fontinalis) and freshwater pearl mussel (Margaritifera margaritifera) in northern Europe. Aquatic Conservation: Marine and Freshwater Ecosystems 26: 1130-1144.

Salonen, J. K., P.-L. Luhta, E. Moilanen, P. Oulasvirta, J. Turunen \& J. Taskinen, 2017. Atlantic salmon (Salmo salar) and brown trout (Salmo trutta) differ in their suitability as hosts for the endangered freshwater pearl mussel (Margaritifera margaritifera) in northern Fennoscandian rivers. Freshwater Biology 62: 1346-1358.

Sparks, B. L. \& D. L. Strayer, 1998. Effects of low dissolved oxygen on juvenile Elliptio complanata (Bivalvia: Unionidae). Journal of the North American Benthological Society 17: 129-134.

Strayer, D. L., 2014. Understanding how nutrient cycles and freshwater mussels (Unionoida) affect one another. Hydrobiologia 735: 277-292.

Strayer, D., S. E. May, P. Nielsen, W. Wollheim, \& S. Hausam, 1997. Oxygen, organic matter, and sediment granulometry as controls on hyporheic animal communities. Archiv fur Hydrobiologie 140: 131-144.

Strayer, D. L., J. A. Downing, W. R. Haag, T. L. King, J. B. Layzer, T. J. Newton \& S. J. Nichols, 2004. Changing perspectives on pearly mussels, North America's most imperiled animals. BioScience 54(5): 429-439.

Taskinen, J. \& M. Saarinen, 2006. Burrowing behaviour affects Paraergasilus rylovi abundance in Anodonta piscinalis. Parasitology 133: 623-629.

Vaughn, C., 2018. Ecosystem services provided by freshwater mussels. Hydrobiologia 810: 15-27.

Vaughn, C. \& C. Hakenkamp, 2001. The functional role of burrowing bivalves in freshwater ecosystems. Freshwater Biology 46: 1431-1446.

Watters, G. T., S. H. O'Dee, et al., 2001. Patterns of vertical migration in freshwater mussels (Bivalvia: Unionoida). Journal of Freshwater Ecology 16: 541-549.

Wood, P. J. \& P. D. Armitage, 1997. Biological effects of fine sediment in the lotic environment. Environmental Management 21: 203-217.

Yeager, M. M., D. S. Cherry \& R. J. Neves, 1994. Feeding and burrowing behaviors of juvenile rainbow mussels, Villosa iris (Bivalvia:Unionidae). Journal of the North American Benthological Society 13: 217-222.

Young, M. R. \& J. C. Williams, 1983. Redistribution and local recolonisation by the freshwater pearl mussel Margaritifera margaritifera (L.). Journal of Conchology 31: 225-234.

Young, M. R. \& J. C. Williams, 1984. The reproductive biology of the freshwater pearl mussel Margaritifera margaritifera (Linn.) in Scotland. II. Laboratory studies. Archiv für Hydrobiologie 100: 29-43.

Young, M. R., P. J. Cosgrove \& L. C. Hastie, 2001. The Extent of, and Causes for, the Decline of a Highly Threatened Naiad: Margaritifera margaritifera. In Bauer, G. \& K. Wächtler (eds), Ecology and Evolution of the Freshwater Mussels Unionoida. Springer, Berlin: 337-357. 
Zajac, K. \& T. Zajac, 2011. The role of active individual movement in habitat selection in the endangered freshwater mussel Unio crassus Philipsson 1788. Journal of conchology 40(4): 446-461.
Publisher's Note Springer Nature remains neutral with regard to jurisdictional claims in published maps and institutional affiliations. 